\title{
Michelini, F. y Köchy, K. (eds.). (2020). Jakob von Uexküll and Philosophy. Life, Environments, Anthropology. Routledge. 284 pp.
}

La figura del biólogo estonio Jakob von Uexküll es central al momento de dar cuenta de gran parte de las discusiones filosófico-antropológicas y ontológicas del siglo XX, ya que, a partir de sus investigaciones sobre fisiología y comportamiento animal, inauguró una nueva concepción de la subjetividad, cuyas derivas serán analizadas a lo largo de todo el siglo por los mayores exponentes de corrientes filosóficas tan distintas como el neokantismo, la fenomenología y el posestructuralismo, entre otras. Su concepto de "mundo circundante" (Umwelt) logró redefinir el concepto de "sujeto" en varios sentidos. En primer lugar, ampliando su extensión hasta abarcar a todos los animales al desplazar al ser humano de su posición de excepción, $\mathrm{y}$, en segundo lugar, redefiniendo la relación que los sujetos tienen con su entorno a partir de la noción de "círculo funcional" (Funktionskreis), que, por otro lado, altera la noción de "causalidad lineal" que se utilizaba para explicar los fenómenos biológicos, proponiendo un mecanismo de causalidad retroactivo. Según Uexküll, cada animal se establece como sujeto activo en el centro de su propio mundo circundante y su comportamiento no es explicable en función de estímulos físicoquímicos que lo afectarían desde el exterior, sino conforme a regímenes de percepción y de acción que le son inmanentes.

Dar cuenta de la importancia que los desarrollos de este biólogo tuvieron en la filosofía del siglo XX es el principal objetivo del volumen Jacob von Uexküll and Philosophy, editado por Francesca Michelini y Kristian Köchy. Para cumplir con este propósito y poder abarcar las múltiples aristas y derivas del trabajo de este autor, el libro reúne a especialistas de diversas disciplinas que logran analizar de manera detallada las profundas implicancias que Uexküll tuvo para distintos filósofos y campos del saber, destacando los acuerdos, las críticas y también, en varios casos, las tergiversaciones que se dieron en sus interpretaciones y usos. Este libro llega a cien años de la publicación de uno de los libros más importantes de Uexküll, Theoretical Biology (1920), asegurando sin dudas que la influencia de sus ideas logre prolongarse también a lo largo del siglo XXI.

La primera sección se encarga de establecer el contexto de producción de sus trabajos a partir de un análisis histórico-conceptual de su obra. El capítulo a cargo de Juan Manuel Heredia propone una periodización 
de la trayectoria intelectual del biólogo. A partir de un detallado análisis del desarrollo de su evolución conceptual, se establecen cuatro etapas en su pensamiento que nos permiten entender la manera en que los principales conceptos del autor, como "plan de construcción" (Bauplan), "mundo circundante" (Umwelt), "conformidad a plan" (Planmäßigkeit), "círculo funcional" (Funktionskreis), entre otros, surgen y se integran a su concepción teórica de las ciencias de la vida, culminando, en su última etapa de producción, en la elaboración de una teoría de la significación (Bedeutungslehre) que intenta dar cuenta de la relación entre mundos vivientes heterogéneos. Al mismo tiempo, se relaciona este recorrido con una serie de transformaciones histórico-epistemológicas y con la situación sociopolítica. Por un lado, en contraste con los enfoques diacrónicos y genéticos dominantes en el siglo XIX, se destaca la centralidad que asumen a inicios del XX las perspectivas sincrónicas (como la de Uexküll). Por el otro, se tematiza la ambivalente relación que el biólogo estonio mantuvo con el nazismo.

En el capítulo escrito por Maurizio Espósito encontramos un análisis de la importancia que la filosofía kantiana tuvo en el entramado conceptual de la obra de Uexküll, destacando la extensa reelaboración que este realiza, sobre todo, de los desarrollos de la Critica de la razón pura y no así de la Critica del juicio, como podría esperarse de un anti-mecanicista. Se detallan los múltiples corrimientos que Uexküll realiza respecto a la obra del filósofo de Königsberg, los cuales le permiten utilizarla para abogar por sus propios objetivos: establecer la independencia de la biología respecto del resto de las ciencias y afirmar un concepto de "subjetividad animal".

Kristian Köchy dedica un capítulo a la influencia de la obra uexkülliana en la biología y la biofilosofía, destacando el papel preponderante que tuvo en campos como la fisiología comparada, la etología y la psicología a partir de su abordaje holístico. En este sentido, resalta su importancia epistemológica, así como su valor para pensar una ética ambiental. Como concluye Köchy, Uexküll nos plantea la necesidad de tomar en cuenta la perspectiva de los propios animales a la hora de considerar los problemas ecológicos que nuestra actualidad nos plantea, entendiéndolos a su vez como sujetos activos que presentan una relación única e inescindible con su Umwelt.

Una serie de capítulos en la segunda parte del libro muestran la profunda y diversa influencia que el biólogo estonio tuvo en la filosofía. El abordaje de Uexküll nos obliga a pensar más allá de lo humano o, 
mejor aún, a pensarnos en relación con el resto de los animales. A lo largo de su obra podemos encontrar ejemplos relacionados tanto con la vida animal como con el ser humano sin que se haga una distinción esencial explícita entre ellos. En este sentido, resulta esperable que entre los primeros filósofos en los que tuvieron eco sus trabajos se encuentren los autores relacionados a la antropología filosófica. En el capítulo escrito por Ralf Becker se tematiza el uso que Max Scheler hizo de Uexküll en su crítica ético-política al mecanicismo y al darwinismo, insertándola en un cuestionamiento más amplio hacia toda la cultura moderna por entender la vida a partir de valores utilitarios. Por otro lado, en el capítulo destinado a la lectura de Helmuth Plessner, HansPeter Krüger despliega un complejo entramado de acuerdos y tensiones que se establecen entre la filosofía de la vida de dicho autor y la obra de Uexküll. A diferencia de Uexküll, Plessner subraya que los seres humanos habitan en un "mundo abierto" (posición que en la época también era sostenida por Scheler y Heidegger). En el capítulo escrito por Carlo Brentari se analiza cómo Ernst Cassirer, a partir de una lectura parcial de la obra de Uexküll e ignorando pasajes que contradicen explícitamente su posición, utiliza los conceptos de "mundo circundante" y "círculo funcional" para desarrollar su concepción del ser humano como animal symbolicum, estableciendo así una diferencia cualitativa frente al resto de los animales.

Para notar el interés que Uexküll tuvo en mostrar la naturaleza semiótica inherente a todo el reino animal y no restringirla solamente al ámbito humano, resulta de particular interés el capítulo escrito por Kalevi Kull, uno de los mayores especialistas en biosemiótica. En él se describen los profundos cambios que al interior de la biología actual se están produciendo al considerar los procesos biológicos como relaciones de significación. Esto posibilita reincorporar una cierta noción de "subjetividad" a la biología y abre todo un nuevo campo de problemas a explorar. Kull logra mostrarnos que la importancia de Uexküll no se limita al plano de la biología, sino que desde su redescubrimiento en la década de los ochenta puede ser entendido como un clásico de la semiótica en general. Por otro lado, marca la importancia que tiene el concepto de "círculo funcional" como mecanismo fundamental para la creación de sentido, lo que explica el interés que despertó en varios campos y las múltiples reapropiaciones que experimentó.

Otro capítulo importante de esta obra es el que Francesca Michelini le dedica a la interpretación que Martin Heidegger hace del trabajo de 
Uexküll, principalmente en los cursos que dicta en Friburgo en 19291930 (publicados bajo el título "Los conceptos fundamentales de la metafísica"). Como muestra la autora, el filósofo alemán encuentra en el biólogo estonio una manera coherente de evitar el mecanicismo sin recaer en los vitalismos más clásicos. Sin embargo, utiliza la concepción no jerárquica de la naturaleza y la imbricación que se da entre el animal y su medio para justificar una diferencia esencial que separa al hombre del resto de los seres vivos, alterando en gran medida la posición del propio Uexküll. En íntima relación con este capítulo podemos encontrar el de Marco Mazzeo, en el que se utiliza la figura de Uexküll para dar cuenta de la discusión que Agamben plantea sobre la concepción heideggeriana del aburrimiento utilizando uno de los ejemplos más célebres entre los muchos que aparecen a lo largo de la obra de Uexküll: la vida de la garrapata. A su vez, Mazzeo tematiza las consecuencias que conlleva el concepto de "mundo circundante" en el plano político a partir del análisis agambeniano, pero también llevando a cabo una elaboración personal de la problemática. La consideración de la gran diversidad de mundos circundantes que se encuentran al interior de la especie humana nos lleva a preguntarnos por la posibilidad de llegar a acuerdos e instancias intersubjetivas. Para abordar esta temática resulta de interés el capítulo escrito por Jui-Pi Chien, en el que se destaca cómo conceptos como el de "círculo funcional" resultan de gran valor para pensar modelos que expliquen la manera en la que se da la cooperación, el altruismo y la comunicación en general, no solo entre individuos sino también entre distintos saberes.

Otro de los campos en el que las ideas del biólogo estonio encontraron un uso profuso es en el área de la fenomenología. Cornelius Borck analiza el caso de Hans Blumenberg, quien vio la posibilidad de extender las derivas del concepto de Umwelt hacia el Lebenswelt (mundo de la vida humano). En este sentido, Borck remarca que la torsión buscada por Blumenberg implica el paso desde una bioepistemología hacia una fenomenología. Otra relación con este campo filosófico se puede encontrar en el capítulo escrito por Tristan Moyle, donde se analiza el diálogo que Merleau-Ponty entabla con la obra de Uexküll en el segundo de sus cursos sobre el concepto de "naturaleza" (1957-1958) en el Collège de France. Moyle destaca la importancia que en el filósofo francés asumen los conceptos uexküllianos de Umwelt, "melodía" y "armonía", así como su valor para pensar un comportamiento significativo previo a 
la consciencia y, más aún, una cultura animal, inserta en una dimensión de inter-animalidad previa a la inter-subjetividad humana.

La afirmación anti-darwinista de Uexküll, según la cual hay una relación armónica y perfecta entre los organismos y su medio de existencia, fue uno de los tópicos que generó extenso debate. El capítulo escrito por Agustín Ostachuk analiza el modo en que esta cuestión es tematizada en Georges Canguilhem y Kurt Goldstein. Si bien ambos comparten con el biólogo estonio una serie de críticas a la centralidad que el esquema de la lucha por la supervivencia asume en Darwin, se oponen a su concepto de "conformidad a plan" (que se encuentra a la base de la concepción uexkülliana de la armonía de la naturaleza). Por otro lado, esta discusión nos conduce al capítulo que Felice Cimatti le dedica al desarrollo de la lectura de Deleuze y Guattari sobre la obra de Uexküll, la cual resulta clave para la formulación de una ontoetología, en la que se busca superar la dicotomía sujeto-objeto y crear una concepción de "animalidad" que no sea simplemente el reverso de lo humano.

La diversidad de temas, autores y perspectivas que encontramos en este volumen es un reflejo de la potencia que la obra de Jacob von Uexküll tuvo en el pensamiento filosófico en los últimos cien años. Sin embargo, quedan fuera de consideración en este volumen otros autores que encontraron en la obra del biólogo estonio importantes puntos de apoyatura para el despliegue de sus propios desarrollos teóricos. Entre estos autores podemos mencionar el caso de José Ortega y Gasset, quien incluso escribió el prólogo a la edición en español de uno de los libros más importantes de Uexküll, Ideas para una concepción biológica del mundo. Su influencia en el filósofo español puede evidenciarse en la importancia que este último le da a la relación entre el hombre y sus circunstancias, y en su noción de "razón vital". Otro autor que no fue tenido en cuenta es Peter Sloterdijk, cuyas menciones a la obra del biólogo estonio son menos numerosas pero no por eso menos importantes. En su tratamiento del problema de la comunidad a partir del concepto de "esferas" se hacen patentes los vínculos conceptuales que mantiene con las "pompas de jabón" de Uexküll, célebre metáfora utilizada para entender el concepto de Umwelt.

De todos modos, estas ausencias no alcanzan a opacar el intento de abarcar gran parte de las resonancias producidas por la obra del biólogo estonio y el esfuerzo que los autores realizaron para poner en diálogo sus trabajos con el resto de los capítulos de este volumen. Esto último 
hace que, además de lograr el objetivo de establecer la influencia que Uexküll tuvo en la filosofía contemporánea, permite pensarlo como un interesante pivote a partir del cual poder relacionar a los diferentes filósofos entre sí. Siguiendo el espíritu holista del propio biólogo estonio, podríamos decir que este volumen en su conjunto resulta ser más que la suma de los artículos que lo conforman. No obstante, su interés no es solamente histórico, ya que, como señala Ezequiel Di Paolo en el epílogo del libro, los conceptos esbozados por Uexküll conservan un gran valor al momento de generar nuevas formas de pensamiento que aborden las problemáticas actuales. Sin dudas, este libro constituye un importante aporte al conocimiento no solo de la obra de Uexküll, sino de la filosofía contemporánea en general, y augura un vasto campo de desarrollo para nuevas investigaciones.

Maximiliano Sebastián Beckel Universidad de Buenos Aires mbeckel@leloir.org.ar 